\title{
LA JUSTICIA TRANSICIONAL COMO MECANISMO DE RECONCILIACIÓN EN EL ESTADO COLOMBIANO
}

\author{
Transitional Justice As A Mechanism Of Reconciliation In The Colombian State
}

\author{
Mildre Yurani HERNÁNDEZ RAMÍREZ *
}

Sumario:

I. Introducción II. Víctimas y justicia transicional III. Marco constitucional y doctrinario de la reconciliación IV. Desafíos de la generación de la paz V. Conclusiones

Resumen: El presente artículo tiene por objeto analizar la implementación de la justicia transicional como mecanismo de reconciliación, a través de procesos judiciales y extrajudiciales, establecidos en el acuerdo final para la terminación del conflicto y la construcción de una paz estable y duradera, pactado entre el Gobierno Nacional Colombiano y el grupo armado FARC-EP (fuerzas armadas revolucionarias de Colombia - ejército del pueblo), con la finalidad de reemplazar un estado de guerra civil, por un orden social pacífico de mediación. Particularmente, el diseño de cada Estado, refiriéndonos al colombiano, en donde se concilia el deber supremo de la memoria histórica, la reconstrucción de la ciudadanía, la nación y el mercado con la justicia.

Palabras clave: Justicia transicional, Víctimas, Reconciliación, Paz, Ciudadanía

Abstract: The purpose of this article is to analyze the implementation of transitional justice as a reconciliation mechanism, through judicial and extrajudicial processes, established in the final agreement for the end of the conflict and the construction of a stable and lasting peace, agreed between the Colombian National Government and the armed group FARC-EP (Revolutionary Armed Forces of Colombia - People's Army), with the aim of replacing a state of civil war with a peaceful social order of mediation. Particularly, the design of each State, referring to the Colombian one, where the supreme duty of the historical memory is reconciled, the reconstruction of the citizenship, the nation and the market with justice.

Keywords: Transitional justice, Victims, Reconciliation, Peace, Citizenship

* Abogada egresada de la Universidad Industrial de Santander (UIS), Colombia, Maestra en Justicia Constitucional egresada de la Universidad de Guanajuato, México. 


\section{Introducción}

El presente trabajo trata de una perspectiva jurídica constitucional que parte del análisis del proceso de paz que se adelantó entre los representantes del Gobierno de la República de Colombia y el grupo armado FARC-EP (fuerzas armadas revolucionarias de Colombia - ejército del pueblo). Para ello, partimos de un breve estudio de las dinámicas de generación de la violencia, para posteriormente relacionar los mecanismos judiciales y extrajudiciales del acuerdo final para la terminación del conflicto armado y la construcción de una paz estable y duradera.

En este sentido, el trabajo pretende dar respuesta a la pregunta: ¿Es la justicia transicional el mecanismo idóneo, a través de procesos de transición de promoción de la verdad, la justicia, la reparación y las garantías de no repetición, y tras las violaciones manifiestas de las normas internacionales de derechos humanos, para lograr la reconciliación en el ordenamiento jurídico?; y, como paso siguiente, hacemos una breve relación descriptiva de la normativa expedida para la implementación y desarrollo del acuerdo en mención, y las interpretaciones realizadas por la Corte Constitucional colombiana.

Por otro lado, se plantea la relevancia de que la paz es un proceso humano auténtico, el cual no resuelve los conflictos, sino que los hace visibles. Porque la paz puede ser mucho más compleja que la guerra, toda vez que en dicho proceso se tiene que escuchar y ponerse de acuerdo con el otro; es una transformación de la colectividad humana que se centra en la disponibilidad al cambio y al perdón y que contiene las especificidades de cada pueblo para trascender en la materialización de la superación de las discrepancias. Porque las modificaciones se dan a través de propuestas que conllevan a resolver las diferencias ideológicas y políticas, pero hay que tener en cuenta que estas mismas pueden crear nuevos problemas, con lo cual, se hace necesario identificar las necesidades básicas de las desigualdades y transformarlas.

También se elabora una breve relación descriptiva de los mecanismos de esclarecimiento de la verdad para la reparación de las víctimas, al objeto de llegar a las causas profundas del mismo. Según Johan Galtung ${ }^{1}$, las diferencias son como un triángulo en donde la punta superior representa la "violencia directa", que está relacionada con el comportamiento y que es la parte visible del conflicto, física y verbal; pero a su vez, están presentes dos prototipos de violencia en cada esquina del ángulo, los cuales no se logran contemplar directamente: 1) la violencia cultural, la cual altera las actitudes de las personas hacia la trasgresión de los derechos humanos y de los arraigos simbólicos que definen su ser, como la religión, el arte, la filosofía, la educación, la ciencia, el lenguaje y la política; y 2) la violencia estructural, la cual trasgrede las necesidades humanas básicas (supervivencia, bienestar, identidad y libertad) ${ }^{2}$, omitiéndolas y generalizándolas en un

\footnotetext{
${ }^{1}$ La presente investigación se sustenta en el estudio y análisis de la teoría de los conflictos del matemático y activista de la escuela irenológica de la sociología de la paz, Johan Galtung, quien fue uno de los pioneros en el tema, considerado por la autora como un punto teórico referencial en este nuevo campo del conocimiento, además de su amplia experiencia como escritor, profesor, conferencista, asesor y mediador en más de cuarenta conflictos y fundador del primer instituto de investigaciones sobre la paz.

2 Hueso García, Vicente (2000), "Johan Galtung: la transformación de los conflictos por medios pacíficos", Cuadernos de estrategia, Ideas sobre la prevención de conflictos, núm. 11, Madrid, Instituto Español de Estudios Estratégicos, III serie, pp. 125-159. [en línea] disponible en: http://www.ieee.es/publicaciones-new/cuadernos-de-estrategia/2000/Cuaderno_111.html. [consulta: 07 de abril de 2017].
} 
solo tipo. La solución de esta violencia está en diferenciar dichas necesidades para trabajar en cada una de ellas con los mecanismos adecuados a través de la justicia transicional.

Los conflictos sociales que permean la historia de la humanidad, en especial la de Colombia, se dan a través de una desesperanza aprendida heredada por quienes no han trascendido (moral, económicamente, etc.), y que inicia en los micro-conflictos: dentro y entre las personas, trasladándose luego a los meso-conflictos: en las sociedades, los cuales se reflejan prontamente en los macro-conflictos: entre los Estados y las Naciones, materializándose finalmente en los mega-conflictos: entre regiones y civilizaciones. En todos los casos siempre habrá sido necesario un proceso de paz que agregue conocimiento sobre cómo convivir en condiciones históricamente diferentes a la guerra y al conflicto.

La relevancia de las víctimas del conflicto armado en Colombia y la justicia transicional forma parte del debate público no sólo en países que han puesto fin a las colisiones armadas sino, también, en aquellos que han asumido el rol de una efectiva transición en respuesta a la apatía social y a la irresponsabilidad gubernamental en el ámbito local y nacional desde el problema.

\section{Víctimas y justicia transicional}

Al finalizar la segunda guerra mundial, la población ha experimentado en distintos lugares del continente el surgimiento de nuevos conflictos armados tanto de carácter interno cuanto de externo; han sido diversas las razones de las discrepancias emanadas. Datos evaluados manifiestan la idea de que, como especie humana, aún no hemos aprendido a vivir en condiciones totalmente pacíficas, razón por la cual, al año 2014 se han desplegado 254 conflictos en 155 lugares diferentes, donde las formas en que fueron resueltos, la mayoría de ellos, hacen referencia a un acuerdo de paz ${ }^{4}$.

En el Estado colombiano existe un conflicto armado interno considerado por la comunidad internacional como el más antiguo del hemisferio occidental, por sus más de cincuenta años de enfrentamientos. Es una colisión de intereses, formas y medios para financiar la resistencia de cada uno de los bandos. Existe desde la confrontación bipartidista entre liberales y conservadores, arrojando como resultado la conformación de diversos grupos armados, en distintos territorios del país, cuyo ideal se centró en la toma violenta del poder político y en la adquisición de tierras rurales de manera ilegal y a mano $\operatorname{armada}^{5}$. La raíz de estas discrepancias se encuentra en la desigualdad social y económica que caracteriza las dinámicas de integración en el país.

Uno de los actores más importantes en el conflicto es el grupo armado FARC-EP (fuerzas armadas revolucionarias de Colombia - ejército del pueblo) que desde el año 2012, junto con el Gobierno Nacional, acuerdan el inicio de las conversaciones directas e

\footnotetext{
3 Galtung, Johan (2004), Trascender y transformar, traducción de Montiel Fernando, México, Montiel y Soriano Editores S.A. de C.V.

4 Vicenç Fisas, Armengol (2015), Anuario de Procesos de Paz 2015, 10 ${ }^{\mathrm{a}}$ ed., Barcelona, Icaria editorial, [en línea] disponible en: http://escolapau.uab.es/img/programas/procesos/15anuarie.pdf. [consulta: 06 de junio de 2017].

5 Centro Nacional de Memoria Histórica (2013), ¡Basta ya! Colombia: Memorias de guerra y dignidad, Bogotá [en línea] disponible en: http://www.centrodememoriahistorica.gov.co/descargas/informes2013/ bastaYa/resumen-ejecutivo-basta-ya.pdf. [consulta: 07 de agosto de 2017].
} 
inintrrumpidas con el propósito de alcanzar un Acuerdo Final para la terminación del conflicto que contribuya a la construcción de la paz estable y duradera. Como pacto político este es uno de los mecanismos para la aplicación de la justicia transicional que surge como una idea alternativa de la comunidad internacional para superar las graves violaciones a los derechos humanos y las infracciones al derecho internacional humanitario. Se trata de un conglomerado de 558 disposiciones (compromisos observables y medibles) divididos en 74 subtemas, 18 temas y 6 puntos: La política de desarrollo agrario, la participación política, el fin del conflicto como proceso integral y simultáneo, la solución al problema de las drogas ilícitas, las víctimas y la implementación, verificación y refrendación ${ }^{6}$.

La confrontación armada en Colombia ha dejado más de ocho millones de víctimas ${ }^{7}$, las cuales sufrieron múltiples tipos de violencia, como desplazamiento, despojo y abandono de tierras, homicidios, violencia sexual, masacres, minas antipersonales, tortura, ejecuciones extrajudiciales, secuestros, ataques a poblaciones, reclutamiento y desaparición forzada ${ }^{8}$.

La doctrina refiere que el derecho internacional público se divide en, derecho internacional de los derechos humanos y derecho internacional humanitario, y si bien estos dos tipos de derecho poseen una coincidencia fundamental, que es la protección de la dignidad y de la persona humana, el derecho internacional humanitario debe entrar primero a nivel internacional y posteriormente actuar a nivel nacional. En lo que se refiere a su contenido, éste representa un derecho objetivo o derecho de emergencia, ya que se aplica a los conflictos armados 9 .

Por esto, en el año 2011, el Congreso de la República de Colombia estableció medidas específicas de atención, asistencia y reparación para:

Todas aquellas personas que individual o colectivamente hayan sufrido un daño por hechos ocurridos a partir del $1^{\circ}$ de enero de 1985, como consecuencia de infracciones al Derecho Internacional Humanitario o de violaciones graves y manifiestas a las normas internacionales de Derechos Humanos, ocurridas con ocasión del conflicto armado interno ${ }^{10}$.

${ }^{6}$ Acuerdo Final para la terminación del Conflicto Armado y la Construcción de una Paz Estable y Duradera. [en línea] disponible en: http://www.altocomisionadoparalapaz.gov.co/herramientas/Documents/ Acuerdo-Final-AF-web.pdf. [consulta: 15 de diciembre de 2017].

7 Registro Único de Víctimas. Red Nacional de Información. [en línea] disponible en: https://rni.unidadvictimas.gov.co/RUV. [consulta: 15 de febrero de 2018].

8 Datos tomados de la Unidad de Víctimas. [en línea] disponible en: https://www.unidadvictimas.gov.co/. [consulta: 10 de enero de 2018].

Centro de Memoria Histórica. en línea] disponible en: http://www.centrodememoriahistorica.gov.co/. [consulta: 15 de enero de 2018].

Dirección para la Accion Integral contra Minas Antipersonal. [en línea] disponible en: http://www.accioncontraminas.gov.co/Paginas/AICMA.aspx [consulta: 10 de febrero de 2018].

9 De ello hizo mérito Juana Inés Jiménez, en su artículo de derechos humanos de título: "Diferencias entre el derecho internacional humanitario y el derecho internacional de los derechos humanos", publicado el tres de septiembre de dos mil dieciséis, en el periódico Milenio de México, citado por José Guadalupe de la O Soto, en "El Derecho Internacional de los Derechos Humanos a la luz del caso Radilla Pacheco vs. México", Revista Contribuciones a la Ciencias Sociales, octubre-diciembre de 2016. [en línea] disponible en: http:www.eumed.net/rev/cccss/2016/04/radilla.html. [consulta: 15 de junio de 2018].

${ }^{10}$ Ley de Víctimas 1448 de 2011. Diario Oficial de la República de Colombia, Bogota D.C., 48096 de junio 
De acuerdo con la ley, se establece una caracterización específica dentro del conflicto armado interno, lo cual tiene un significativo resultado en términos de definición de los actores y en particular del rol de las víctimas, para lograr la reconciliación en el proceso de paz. La terminación de las confrontaciones armadas por la vía del diálogo y la negociación permite la cesación de los daños y las violaciones de los derechos de la población.

Es a través del proceso de paz que las víctimas del conflicto armado se centran en un nuevo impulso de reconocimiento, en que el numeral quinto del acuerdo político en mención ${ }^{11}$ establece un conjunto de políticas públicas que conllevan a ampliar una vez más las prerrogativas jurídicas. Se inicia con una declaración de principios (reconocimiento de las víctimas, reconocimiento de responsabilidad, satisfacción de los derechos de las víctimas, participación de las víctimas, esclarecimiento de la verdad, reparación de las víctimas, garantías de protección y seguridad y garantías de no repetición, reconciliación $\mathrm{y}$ enfoque de derechos $)^{12}$, los cuales guían el sistema integral de mecanismos judiciales y extrajudiciales, complementarios y condicionantes entre sí, mediante la unidad para la búsqueda de personas desaparecidas, la jurisdicción especial para la paz, la comisión para el esclarecimiento de la verdad, la convivencia y la no repetición, las medidas de reparación integral para la construcción de la paz y las garantías de no repetición ${ }^{13}$; estos principios forman parte de los objetivos de la justicia transicional y se adaptan a cada situación de conflicto específico con la finalidad general de rendir cuentas de lo sucedido y reparar a las víctimas.

Por ende, definir la justicia transicional como concepto es algo complejo, toda vez que no existe en la doctrina especializada un concepto unívoco del término: debido a su carácter amplio y flexible, así como al contexto geopolítico y socioeconómico en el que es aplicado y la forma en que es implementado ${ }^{14}$, su justificación emerge de las experiencias prácticas que han empleado diversas medidas para frenar los procesos de transición en los que aquélla operará ${ }^{15}$. La categorización propuesta por la Secretaría General de las Naciones Unidas es la unificación de procedimientos y mecanismos asociados con los intentos de una sociedad por dar término a una larga historia de abusos a gran escala, en aras de garantizar la responsabilidad, servir a la justicia y alcanzar la reconciliación ${ }^{16}$.

Es así como surge el cuestionamiento de por qué existe este modelo específico de justicia transicional para la reparación de las víctimas en un país donde la misma población

10 de 2011. [en línea] disponible en: http://www.alcaldiabogota.gov.co/sisjur/normas/Norma1.jsp?i=43043. [consulta: 15 de junio d 2017].

${ }^{11}$ Acuerdo Final para la terminación del Conflicto Armado y la Construcción de una Paz Estable y Duradera. [en línea] disponible en: http://www.altocomisionadoparalapaz.gov.co/procesos-y-conversaciones/ Documentos\%20compartidos/24-11-2016NuevoAcuerdoFinal.pdf. [consulta: 24 de noviembre de 2017].

12 Ídem.

13 Ídem.

${ }^{14}$ Cubides CÁrdenas, Jaime y Vivas Barrera, Tani Giovanna (2016), La justicia transicional y el rol de la Corte Interamericana de Derechos Humanos. A propósito del posible acuerdo de paz en Colombia, $10^{\mathrm{a}}$ ed., Bogotá, Universidad Católica de Colombia, p 154.

15 Bernal CuÉllar, Jaime, et al., (2016), Reflexiones jurídicas sobre el proceso de paz, Bogotá, Universidad Externado de Colombia, pp 13 Y 124.

${ }^{16}$ Organización de las Naciones Unidas y el Estado de Derecho, Justicia de transición [en línea] disponible en: https://www.un.org/ruleoflaw/es/thematic-areas/international-law-courts-tribunals/transitional-justice/. [consulta: 01 de junio de 2017]. 
no se siente satisfecha con la justicia penal ordinaria y con la política penal del enemigo. En este sentido estimamos que la justicia transicional es un mecanismo alternativo que está integrado por una serie de formas específicas que ayudan a superar largos periodos de conflictos en los que se han violado derechos humanos de manera masiva y sistemática; y es a través de la reparación, la reconciliación y la restauración, que se pueden adelantar procesos penales, investigaciones, esclarecimiento de la verdad y reformas jurídicas e institucionales. Es un enfoque diferente que no sustituye los procesos judiciales ordinarios, sino que los complementan con otras medidas, en las cuales se puede llegar a recuperar la confianza y prevenir nuevos abusos que, según la experiencia comparada, han logrado la reconciliación y la reparación de las víctimas ${ }^{17}$.

En la actualidad, la víctima en la doctrina internacional como concepto, va más allá de la tradicional noción del sujeto pasivo del delito, toda vez a que es aquella persona perjudicada por la violencia mediata $y / o$ indirectamente ${ }^{18}$. Por ende, constituye una de las cuestiones más relevantes en los debates acerca de la justicia internacional de los derechos humanos y de la justicia transicional.

\section{Marco jurídico y constitucional de la reconciliación}

La paz, en el ordenamiento jurídico colombiano, es un valor fundamental y un derecho de obligatorio cumplimiento que le corresponde a toda persona como ciudadano. De rango internacional y constitucional, los elementos de la carta política de 1991, ideados como tratado de paz, propician para los fines del Estado Constitucional de Derecho un marco jurídico, democrático y participativo, que posteriormente consagra disposiciones con vigencias temporales, denominadas transitorias, con finalidades inmediatas que propende el Estado como un todo. Recordemos que, como señala José Jesús Soriano Flores:

es correcto afirmar que, al día de hoy, las bases positivas y teóricas delimitadas temporalmente en los años siguientes a la conclusión de la segunda guerra mundial siguen siendo las que han ido acuñando un concepto contemporáneo de derechos humanos [y que] esas bases teóricas están centradas fundamentalmente en la teoría del Estado constitucional de derecho, que posiciona a los derechos humanos y su interpretación, en el lugar más importante de las estructuras jurídicas. ${ }^{19}$

En el ordenamiento colombiano, el escenario constitucional y doctrinario de la reconciliación se desarrolla a través del marco legal para la paz, que inicia con una reforma constitucional (acto legislativo) a través de la cual se ingresan, al interior del cuerpo

\footnotetext{
${ }^{17}$ Ferrajoli, Luigi (2016) "La justicia penal transicional en la Colombia del postconflicto y las garantías para la paz interna"; Revista critica penal y poder, observatorio del sistema penal y los derechos humanos de la Universidad de Barcelona, núm.10, pp, 146-161, [en línea] disponible en: http://revistes.ub.edu/ index.php/CriticaPenalPoder/article/view/15489, [consulta: 03 de agosto de 2017].

${ }^{18}$ Beristáin, Antonio (2017) "Hoy y mañana de la justicia y la sociedad en México (los derechos humanos y el combate a la delicuencia)", en La justicia nexicana hacia el siglo XXI. México, UNAM, Instituto de Investigaciones Jurídicas/Senado de la República/LVI Legislatura, p. 489.

${ }^{19}$ Soriano Flores, José Jesús (2018) "Elementos históricos y jurídicos para la conceptualización contemporánea de los Derechos Humanos", en Revista Anuario de Derechos Humanos del Instituto de la Judicatura Federal, México, Suprema Corte de Justicia de la Nación, pp. 374-375, [en línea] disponible en: https://www.ijf.cjf.gob.mx//Sitio2016/include/sections/Anuario/Capitulos\%20Anuario\%202017/14-Elementos\%20 hist\%C3\%B3ricos\%20y.pdf, [consulta: 15 de agosto de 2018].
} 
jurídico de la ley fundamental, determinadas normas de carácter transitorias que son el instrumento reglamentario de la justicia transicional.

La primera reforma, en el año 1997 a través de la ley 418, otorgó la facultad al Presidente de la República para realizar negociaciones con actores políticos armados. La segunda enmienda para el país, en el año 2011, consagró la ley 1448 de acuerdo con lo establecido en los convenios de Ginebra y el Derecho Internacional Humanitario, donde se precisa el reconocimiento de un conflicto armado interno: todo enfrentamiento protagonizado por grupos de diferente indole (tales como fuerzas militares regulares o irregulares, guerrillas, grupos armados de oposición, grupos paramilitares, o comunidades étnicas o religiosas), que utilizando armas u otras medidas de destrucción provocan más de 100 víctimas en un año ${ }^{20}$. Con esto se originó el avance hacia la construcción de una paz sostenible que responda a las causas que dieron origen al conflicto.

Es así como a partir de estas normas de reconocimiento y facultades se consagra en el artículo 22 del Título Segundo de los Derechos, las Garantías y los Deberes, Capítulo Primero de los Derechos Fundamentales en la Constitución Política colombiana, que la paz es un derecho básico y un deber de imprescindible cumplimiento, por lo cual, la norma transitoria (Art.66) determina:

Los instrumentos de justicia transicional serán excepcionales y tendrán como finalidad prevalente facilitar la terminación del conflicto armado interno y el logro de la paz estable y duradera, con garantías de no repetición y de seguridad para todos los colombianos; y garantizarán en el mayor nivel posible, los derechos de las víctimas a la verdad, la justicia y la reparación $n^{21}$...2 $^{22}$

La Corte Constitucional decide complementar dicha disposición en relación directa con la reconciliación:

La justicia transicional está constituida por un conjunto de procesos de transformación social y política profunda en los cuales es necesario utilizar gran variedad de mecanismos con el objeto de lograr la reconciliación $n^{23}$ y la paz, realizar los derechos de las víctimas a la verdad, justicia y reparación, restablecer la confianza en

\footnotetext{
${ }^{20}$ Escola de Cultura de Pau (2015), Alerta 2015! Informe sobre conflictos, derechos humanos y construcción de paz, Barcelona: Icaria. [en línea] disponible en: http://escolapau.uab.cat/img/programas/alerta/ alerta/15/alerta15e.pdf. [consulta: 26 de agosto de 2017].

${ }^{21}$ Énfasis propio. Una vez realizado el estudio del test de ponderación desarrollado por la Corte Constitucional colombiana en la Sentencia C - 579 DE 2013, respecto al problema jurídico del cumplimiento de los compromisos del Estado Social y Democrático de Derecho, de respeto, protección y las garantías de los derechos humanos de la sociedad y en especial de las víctimas del conflicto armado interno, vinculadas con la justicia transicional como mecanismo para fomentar las obligaciones en mención, cuyo debate demuestra la complejidad de la trascendencia de la paz a nivel constitucional y la caracterización de la reconciliación como mecanismo de reparación y herramienta institucional judicial y extrajudicial, para logar la realización de los principios de la justicia, la construcción de la verdad y la paz.

${ }^{22}$ Congreso De La República De Colombia. Acto Legislativo 01 del 31 de Julio de 2012. [en línea] disponible en: http://www.secretariasenado.gov.co/senado/basedoc/acto_legislativo_01_2012.html. [consulta: 15 de mayo de 2017].

${ }^{23}$ Énfasis propio, en relación con la cita número 23, se puede determinar que la reconciliación es un mecanismo de reparación en los procesos de paz, verdad y justicia, son dos componentes que se desarrollan entre sí a través de políticas y programas específicos en la superación de los daños causados en el conflicto armado interno colombiano.
} 
el Estado y fortalecer la democracia, entre otros importantes valores y principios constitucionales ${ }^{24}$.

Son dos instrumentos que necesariamente están relacionados entre sí y que siguen las determinaciones del Consejo de Seguridad de Naciones Unidas sobre el tema. Por ello, la reconciliación se estudia como el mecanismo de superación de las diferencias sociales para lograr una cultura de paz después de la negociación política con uno de los grupos armados más antiguos del país, medidas que a corto plazo deberán reflejarse en las relaciones del gobierno con la población en general.

Por lo tanto, la materialización de la paz es presentada a través de un plano teórico y filosófico o sobre el derecho positivo, un objeto político y una obligación jurídica prioritaria sobre cualquier otra, porque la paz, como valor político supremo, responde a la finalidad de terminación del conflicto armado interno a través de una justicia especial, misma que no puede ser la justicia ordinaria. La primera razón de lo anterior es de orden jurídico, toda vez que Colombia ha vivido la mayor parte de su historia bajo los rigores de la violencia y se ha decretado en diversas oportunidades el Estado de excepción, lo cual es un instrumento ordinario de la política gubernamental que de una u otra forma ha incidido en la estructura institucional y en la cultura jurídica; la segunda razón es de carácter político, a través del derecho humanitario bélico, en el cual los combatientes no son delincuentes, debido a que el estado de guerra introduce una diferenciación ente los súbditos de la nación beligerante ${ }^{25}$.

Los mecanismos de recuperación de la confianza, la convivencia, la paz y la reconciliación, consagrados en el acuerdo final para la terminación del conflicto y la construcción de una paz estable y duradera, se desarrollan a través de la conciliación entre dos sistemas de juzgamiento: el judicial, con la jurisdicción especial para la paz, y el extrajudicial, con la comisión para el esclarecimiento de la verdad, la convivencia y la no repetición, que se aplicará a los integrantes de las FARC-EP, a los agentes del Estado, víctimas, paramilitares desmovilizados y personas civiles involucradas en el conflicto, y donde lo retributivo y vengativo como justicia se reemplaza por lo restaurativo y lo conciliatorio, sin renunciar a la verdad como figura en desarrollo en lo legislativo, lo constitucional y lo doctrinario. Tratándose así de un argumento jurídico muy debatido, el cual hace referencia a la garantía del nunca más como la manifestación de mayor peso y carácter político en contra de los actos que generaron el conflicto y la impunidad.

La jurisdicción especial para la paz deberá cumplir con los deberes del Estado de investigar, juzgar y sancionar. El primer paso consiste en el reconocimiento de la responsabilidad de los actos que hicieron parte del conflicto y, de esta manera, individualizarlos y tipificarlos como delitos amnistiables o no, indultables o susceptibles de otros tratamientos especiales o equivalentes, por lo cual, se definen situaciones jurídicas, sanciones propias que tendrán una función retributiva y restaurativa mediante la realización de trabajos

\footnotetext{
${ }^{24}$ Corte Constitucional De Colombia. Sentencia C - 579 DE 2013. Magistrado Ponente: Jorge Ignacio Pretelt Chaljub. [en línea] disponible en: http://www.corteconstitucional.gov.co/relatoria/2013/C-579-13. htm. [consulta: 25 de mayo de 2017$].$

${ }^{25}$ Ferrajoli, Luigi (2016) "La justicia penal transicional para la Colombia del postconflicto y las garantias para la paz interna", Revista critica penal y poder. Observatorio del sistema penal y los derechos humanos, Universidad de Barcelona, núm. 10, pp. 146-161. [en línea] disponible en: http://revistes.ub.edu/ index.php/CriticaPenalPoder/article/view/15489/18650. [consulta: 10 de mayo de 2017].
} 
de reparación del daño causado con restricción efectiva de la libertad entre cinco y ocho años, y sanciones alternativas y ordinarias en escenarios carcelarios comunes con penas privativas de la libertad entre cinco, ocho, quince y veinte años. El reglamento de la competencia en mención garantizará la participación de las víctimas dentro de los procesos adelantados en cada una de las salas ${ }^{26}$.

Aquí cabe decir que el mecanismo de justicia es presentado como una alternativa viable, oportuna, eficaz, actual y, sobre todo, efectuado en momentos de transición en donde se despliega una fase de categorización de adecuadas praxis y de estándares legales alternativos, en respuesta al colapso en los sistemas jurisdiccionales de enjuiciamiento tradicional -en los cuales los agentes ilegales del conflicto no se quieren someter al mencionado modelo habitual; por ello, y por el avance en los ordenamientos jurídicos, las transiciones políticas en América Latina han sido consideradas como fundamentales, más que necesarias.

También debe destacarse el origen de las comisiones de la verdad y los factores que influyeron a su establecimiento, como son, la existencia de los escenarios viables de transformación, donde se encuentra la fuerza política que se sobrepone a la fuerza derrotada, la crisis económica, que propicia el conflicto y la falta de credibilidad de determinados sectores de la sociedad, mismos que influyen durante el proceso que se será perfeccionado con una serie de recomendaciones y medidas de reparación a seguir, derivadas de la investigación de crímenes de rango internacional y repudiados por la humanidad.

Al respecto la comisión para el esclarecimiento de la verdad, la convivencia y la no repetición, el mecanismo extrajudicial de investigación de los patrones de violencia no está facultado para impartir justicia, pero sí contribuye a la administración de la misma, porque sus tres objetivos específicos son 1) apoyar a la elucidación de lo ocurrido a través de una explicación amplia de la complejidad de los componentes del conflicto armado, 2) promover el reconocimiento de las víctimas y la convivencia en los territorios más afectados por la guerra armada interna y, 3) propiciar espacios de diálogo en la población en general ${ }^{27}$. El producto de la comisión es un informe final, el cual determinará el contexto histórico de los orígenes, causas y factores de las diferencias que suscitaron el conflicto, las conclusiones y recomendaciones.

Más aun, cuando una nación vive más de media década de conflicto armado interno, las esperanzas de reconciliación y reparación no se logran divisar o sencillamente no se esperan a que lleguen. La pérdida de identidad como pueblo es uno de los componentes más perniciosos de la guerra. Los enfrentamientos armados han sido y seguirán siendo una constante en la historia de la humanidad debido a la crueldad sin límites de grupos e individuos, misma que tendrá que ser contrarrestada con la posibilidad de un estado de justicia y paz donde las necesidades básicas como sobrevivir, el bienestar, la libertad y la identidad, sean garantizadas.

El proceso de reconciliación y reparación se complementa con el planteamiento de medidas de carácter psico-social con fines de rehabilitación, las cuales son integradas desde

\footnotetext{
${ }^{26}$ Acuerdo Final para la terminación del Conflicto Armado y la Construcción de una Paz Estable y Duradera. [en línea] disponible en: //www.altocomisionadoparalapaz.gov.co/procesos-y-conversaciones/Documentos\%20compartidos/24-11-2016NuevoAcuerdoFinal.pdf. [consulta: 24 de noviembre de 2017].

${ }^{27}$ Ídem.
} 
dos perspectivas: la primera, a través de la recuperación emocional a nivel individual para las víctimas de violencia sexual y, la segunda, con programas de reivindicación para la convivencia y no repetición, con un enfoque diferencial y de género. Estos mecanismos son determinantes en la construcción de una sociedad más tolerante o que ha dejado de serlo debido a la ausencia del Estado en los territorios más alejados del casco urbano y que no pasan a formar parte de la institucionalidad del mismo, ni de los avances tecnológicos, las políticas públicas o la educación a causa de la violencia, que no permite que el desarrollo económico trascienda para establecer relaciones laborales que permitan dejar de lado la ilegalidad y la confrontación armada.

Como producto final, la reconciliación es el reconocimiento de los derechos de las víctimas y el fortalecimiento del Estado Social de Derecho y la Democracia ${ }^{28}$, elementos pilares de la justicia en transición de carácter reparador. En ésta se establece la necesidad de la implementación de las comisiones de la verdad, catalogadas como uno de los desarrollos más importantes de la civilización, mediante la cual los conflictos empiezan a ser dilucidados y los crímenes se van admitiendo. Es lo denominado cascada de la justicia, e incluye a todos aquellos procesos en oleada en los cuales la sociedad misma demandó la responsabilidad de los actos cometidos en el marco de la guerra, teniendo siempre en cuenta otros juicios históricos a través de la perspectiva comparada, y que forman parten de la legislación y de las instituciones nacionales e internacionales ${ }^{29}$.

Las consideraciones sobre la justicia en transición radican en una contradicción incesante que, según los expertos en el tema, se debe a que por un lado es necesaria la abstención de una persecución penal y/o del castigo como condición imprescindible para favorecer la paz y la reconciliación y, del otro lado, las amnistías e indultos no aseguran la efectividad de la reconciliación y la sostenibilidad de la paz ${ }^{30}$. Y es debido también a que cada proceso es singular y a que un análisis desde la perspectiva jurídica omite las circunstancias sociopolíticas y la dimensión moral de la justicia, las cuales constituyen los intereses a considerarse durante el proceso.

\section{Desafíos de la generación de la paz}

El posconflicto es el periodo que sigue a la superación total o parcial de los conflictos armados en la consolidación de la paz. En el Estado Colombiano es definido como la fase que viene después de la firma e implementación de los acuerdos de paz. La comunidad internacional referenció dicho afianzamiento hace más de treinta años, gracias a los trabajos realizados por Johan Galtung, quien precisó las estructuras de consolidación para promover una paz duradera, referentes de la definición de las causas profundas que generaron el conflicto y la capacidad originaria de cada Estado para asumir la transición y resolver las colisiones.

Por ende, la Organización de las Naciones Unidas (ONU) a través de la agenda por la paz estableció que la paz no se reduce a la simple firma de un acuerdo entre las partes

\footnotetext{
${ }^{28}$ Martínez Sánchez, Mauricio (2016) Reconciliación y castigo en la justicia transicional. Comparación de los modelos Alemán y Colombiano, Bogotá, Universidad Nacional de Colombia, Grupo editorial Ibáñez.

${ }^{29}$ Sikkink, Kathryn (2013), La cascada de la justicia. Cómo los juicios de lesa humanidad están cambiando el mundo de la politica, Traduccion: PRUNES, María Natalia, Buenos Aires, Argentina, Gedisa, S.A.

${ }^{30}$ Agudelo Mejí, Dimaro et al. (2017), Justicia Transicional, Medellín, Universidad de Medellín, 2017, p. 113.
} 
enfrentadas, sino que es un proceso largo y complejo que incluye al menos tres momentos claves: el establecimiento de la paz (peacemaking), que son las acciones tendientes a la búsqueda de una solución sosegada de las controversias -en el caso específico, a través de la negociación política entre el gobierno y las FARC-EP con el respaldo de la comunidad internacional $^{31}$. De ese modo, la conservación de la paz (peacekeeping) es el apoyo y la orientación política y militar para el estímulo del Estado de Derecho y de las instituciones de seguridad tendientes a logar el desminado, desarme, desmovilización y reintegración ${ }^{32}$; inclusive, la comisión creada por el Consejo de Seguridad y la Asamblea General realiza las acciones tendientes a la consolidación de la paz (peacebuilding) ${ }^{33}$ a través de la promoción de estrategias de reconciliación social, política y económica. Ello porque lo que se quiere prevenir es una recaída en el conflicto armado y que se fortalezca una paz duradera y la seguridad nacional, por ende, es necesario que los demás Estados supervisen y apoyen las estrategias establecidas.

Los propósitos de inspiración, como la generación de la paz, son a corto y a mediano plazo, y en un orden ascendente que inicia en la ciudadanía, se refleja en el Estado y se transforma en el mercado. Se trata de ocuparnos del país que, hasta el momento como nación, no hemos sido capaces de gobernar. El problema que se vislumbra es que el Estado no tiene control sobre la mitad de su territorio; Colombia es un país eminentemente rural y se encuentra en la categoría mundial como uno de los países que cuenta con más población urbana que rural, pues se piensa que vivir en el campo significa ser más pobre, y contar con menos oportunidades de desarrollo y bienestar ${ }^{34}$.

Las instituciones que conforman la organización política no se establecen en las comunidades más alejadas, porque el desarrollo económico, industrial y educativo está en el centro del país, y la violencia y el conflicto armado se encuentra en el campo, donde no hay presencia del gobierno central y la brecha entre las dos formas de vivir son aprovechadas por los grupos armados ilegales para brindar seguridad, justicia y tributación privada de orden ilícito.

Puede decirse que la clave de los acuerdos de paz es desmovilizar los grupos armados irregulares y remplazarlos por instituciones en el territorio, mediante las cuales se procure la prevalencia de la seguridad e inversión pública y el desarrollo rural y productivo, porque lo primero que se acaba con la guerra es la ciudadanía, dado a que se inhibe dicha condición humana y se distorsiona su definición. Porque no son la leyes creadas en el Congreso las que construyen las instituciones en los territorios, sino la acción del ciudadano de demandarlas, organizarse, ejercer el derecho al voto libremente y movilizarse

\footnotetext{
${ }^{31}$ Carta de las Naciones Unidas. Capítulo VI: Arreglo pacífico de controversias. [en línea] disponible en: http://nacionesunidas.org.co/diapersonaldepaz/departamento-de-operaciones-de-mantenimiento-de-lapaz/ [consulta: 20 de octubre de 2017].

${ }^{32}$ Naciones Unidas. Departamento de Operaciones de Mantenimiento de la paz. Consultado en: http:// nacionesunidas.org.co/diapersonaldepaz/departamento-de-operaciones-de-mantenimiento-de-la-paz/ [consulta: 30 de octubre de 2017].

${ }^{33}$ Naciones Unidas. Apoyo de la consolidación de la paz. La consolidación de la Paz y las Naciones Unidas. [en línea] disponible en: http://www.un.org/es/peacebuilding/pbso/pbun.shtml. [consulta: 24 de octubre de 2017].

${ }^{34}$ La brecha entre la Colombia rural y urbana, explicada a través de 9 gráficos. [en línea] disponible en: $h t$ tps://magnet.xataka.com/en-diez-minutos/la-brecha-entre-la-colombia-rural-y-urbana-explicada-a-traves-de-9-graficos [consulta: 25 de febrero de 2018].
} 
para exigir la oferta y demanda de sus derechos políticos, económicos y de inclusión social, porque donde hay instituciones hay Estado y, por ende, puede haber mercado.

Aunque la generación actual de colombianos es la más educada de la historia y de la que dependen las subsiguientes, está claro que no se quiere sacrificar más ciudadanos porque tampoco hay disposición para ello. La guerra no se finaliza a través de la refrendación de un acuerdo político, se acaba porque la sociedad que padece la violencia tiene claro que no está dispuesta a seguir viviendo en ella y que las diversas negociaciones fallidas son experiencias que ayudan a corroborar que estamos en un momento y en una hora especifica de evolución. Debe generarse una conciencia histórica colectiva sobre la paz, como un nuevo paradigma, a través de un proceso de transformación de la cultura con base en las relaciones de Estado-Ciudadano, donde se promueva la transparencia y se rechace la corrupción pública y privada. Generar la consciencia de que tener derecho a los derechos no es un privilegio de unos cuantos sino de toda la población, sin que ello dependa del desarrollo del territorio en cuestión, lo cual fortalecerá la gobernabilidad democrática ${ }^{35}$.

Sin embargo, la potestad con la que cuenta cada Estado para implementar los esquemas de reparación y amnistías, además de administrar justicia, pretende esencialmente generar una modificación en las relaciones entre las víctimas y el gobierno. En este sentido, es posible afirmar que el objetivo constitucional de la carta política del 91 es facultar al representante del ejecutivo nuevamente, con la intención de cesar la acción penal contra los integrantes de las FARC-EP, que han decidido dejar las armas y reintegrarse a la vida civil.

Éste constituye un punto muy importante que cada ciudadano deberá entender para marchar hacia un paradigma diferente, el cual inicia a través de un diseño institucional que ofrezca la confianza a los excombatientes que no hayan cometido delitos de lesa humanidad, genocidio, crímenes de guerra, secuestro, tortura, ejecuciones extrajudiciales, violencia sexual, desplazamiento y reclutamiento de menores ${ }^{36}$, debido a que el precepto normativo consagra que sólo lo delitos de naturaleza política como rebelión, sedición, asonada, conspiración y seducción, usurpación y retención ilegal de mando y los conexos a éste, pueden gozar de dicha exclusión de sanción.

Igualmente, se piensa que Colombia debe adherirse al Derecho Internacional Humanitario y procurar conceder la amnistía más amplia posible en aplicación del principio de favorabilidad regulado y establecido en el artículo 6.5 del Protocolo Adicional II de las Convenciones de Ginebra de $1949^{37}$. La Sala de amnistía e indulto aplicará las sanciones correspondientes conforme a lo establecido en la ley y en el Acuerdo de creación de la Jurisdicción Especial para la Paz.

En ese tenor, todos los ciudadanos deberán asumir el rol de actores generadores de

\footnotetext{
${ }^{35}$ LÓPEZ, Claudia (2017), La visión de una generación para transformar a Colombia, TEDxUExternado. [en línea] disponible en: https://www.ted.com/, [consulta: 15 de febrero de 2017].

${ }^{36}$ Acuerdo Final para la terminación del Conflicto Armado y la Construcción de una Paz Estable y Duradera. [en línea] disponible en: http://www.altocomisionadoparalapaz.gov.co/procesos-y-conversaciones/ Documentos\%20compartidos/24-11-2016NuevoAcuerdoFinal.pdf [consulta: 24 de noviembre de 2017].

${ }^{37}$ Protocolo II adicional a los convenios de Ginebra de 1949 relativo a la protección de las víctimas de los conflictos armados sin carácter internacional, 1977, [en línea] disponible en: https://www.icrc.org/spa/ resources/documents/misc/protocolo-ii.htm [consulta: 24 de noviembre de 2017].
} 
paz, con el fin de no seguir arraigando la necesidad mancomunada de venganza, y que la educación no gire en torno a terminar con aquél que piense y actúe diferente, lo cual permite afirmar que el marco normativo sobre el tema en cuestión es bastante sólido en el ordenamiento jurídico colombiano y que los avances que se han incorporado, de acuerdo con los estándares de juzgamiento basados en experiencias propias y externas, finalmente ayudarán a que la actual práctica se realice con éxito, de acuerdo con lo negociado y pactado a través del acuerdo para la paz.

Además, los procesos de reconciliación que se han desarrollado a lo largo del tiempo demuestran la capacidad humana de encontrar en cada pueblo, a través de sus propios símbolos, la ruta para marchar hacia un paradigma diferente, dejando atrás las dinámicas de la guerra para ponerse de acuerdo y negociar las diferencias, creando nuevas oportunidades. Ejemplo de ello son los procesos de reconciliación en Ruanda, donde pasaron del genocidio a un modelo económico empresarial que brindó nuevas oportunidades a la población en general; el proceso de Sudáfrica como modelo de transición pacífica que consiguió romper con el régimen de segregación racial y convertirse en la nación del arco iris $^{38}$; o Irlanda que, tras quinientos años de guerra, logra cambiar la estructura del odio y violencia por el de la convivencia, creando un nuevo país. Lo cual lleva a afirmar que no existe un gen violento, una guerra y por ende una condena eterna o una razón por la cual una nación tenga que sumirse en un conflicto $\sin \operatorname{fin}^{39}$.

Finalmente, una decisión histórica constituye la circunstancia a través de la cual las condiciones culturales se construyen a través de una mirada individual y colectiva, porque la guerra se agota y las venganzas se perpetúan y hacen que las siguientes generaciones nazcan con un discurso de venganza sin referencia alguna del mismo.

\section{Conclusiones}

El interés por la justicia en transición como concepto en construcción va más allá de la materialización de una definición que sólo se limite al contexto en cuestión, es entender que es una alternativa interesante de examinar en condiciones posibles a través de juicios que aporten a la protección de los derechos humanos y ayuden a resolver los conflictos.

De lo expuesto en este trabajo se observa que la idea de reconciliación es una solución a la crisis de conflictos armados en los ordenamientos jurídicos, y que cumple con la finalidad de superar los abismos sociales que caracterizan la inequidad y desconfianza de la sociedad, por cuanto la justicia transicional se instauró para moderar el carácter de la ecuanimidad a través de la orientación internacional relacionada en tres

\footnotetext{
${ }^{38}$ Término acuñado para hacer referencia al Estado africano como una región política, cultural, pero, sobre todo, en relación directa con la historia y la superación del Apartheid, específicamente en el momento coyuntural cuando el país dejó de ser la nación de la utopía y pasó a ser el de hoy, el que se esfuerza día a día por construir su propia imagen, libre de las influencias de la colonización; Sudáfrica fue reinventada no desde una visión poscolonial sino desde una posición global. Por ende, se hace referencia a la construcción de una identidad propia que evoluciona y reconoce al otro como un igual, siendo quizás el rol que hoy pretenden asumir los sudafricanos, atrayendo para sí, a su manera, el gran mito de la cultura occidental: el football.

${ }^{39}$ Uribe, Diana, Casa de la historia Diana Uribe, [en línea] disponible en: http://www.lacasadelahistoria. $\mathrm{com} /$, [consulta: 25 de agosto de 2017].
} 
etapas, denominadas, superación de experiencias traumáticas, rescate cultural, religioso, espiritual y la reconexión consigo mismo y con los demás a través del dialogo psicopolítico, como lo ha mencionado Martínez Sánchez son mecanismos de pacificación relacionados con tratamientos psicológicos para reconstruir la memoria histórica en los procesos de reconciliación, superación y aprendizaje para vivir con hechos del pasado $\mathrm{y}$ transformar la sociedad.

Cabe mencionar que todos los conflictos parten de discrepancias entre dos o más situaciones, por lo tanto tienen el derecho a ser procesados a través de la reconciliación mediante la trascendencia ("ir más a allá) y la transformación (cambio), versatilidades materializadas en la convivencia entre los integrantes de la sociedad. También se encuentran una multiplicidad de actores, los cuales fueron definidos e incluidos; una segunda medida es la implementación de acciones concretas, operativas y programáticas tendientes a la reparación; y en un tercer momento se encuentra el factor tiempo, en el que nada es instantáneo sino progresivo, debido a las dinámicas establecidas de promulgación por parte del legislativo.

Una última etapa es la restructuración de la ciudadanía, respecto a la resistencia al cambio producto de la desconfianza por la violencia, la polarización de las políticas públicas y la fragmentación de las relaciones sociales, pues los juzgamientos a través de la justicia transicional y por ende las comisiones de la verdad se enlazan mejor en materia de defensa de derechos humanos, toda vez que las disuasiones que estimulan los análisis realizados en países vecinos repercuten más allá de los límites de un solo país, que son realmente las consecuencias inherentes de un incremento de adaptación de las normas y la verosimilitud del castigo en una relación directa con el acotamiento en la cantidad de violaciones a los derechos de la población en general.

Los procesos judiciales y extrajudiciales en mención implican adelantos que se producirán gracias al marco normativo diseñado para ello, pero que van de la mano con la socialización y de la disuasión, porque gracias a las comisiones de la verdad se legitimaron sanciones que antes no existían, que van más allá del encarcelamiento, lo cual da posibilidad de restaurar el honor y la dignidad, porque el castigo que se impone, deberá persuadir a quienes se orientan por la lógica de las consecuencias, según lo señalado por Sikkin. ${ }^{40}$

Particularmente, el 2018 es un año electoral en Colombia, con elecciones presidenciales y legislativas, siendo el mayor reto a corto plazo asumir la reincorporación a la vida civil y política de los excombatientes de la guerrilla de las FARC de manera inclusiva, la cual se verá reflejada en la democracia a través de la participación del partido político del grupo revolucionario en las primeras elecciones tras la firma e implementación de los acuerdos de paz, debido a que los compromisos exitosos son aquellos que cambian las balas por los votos y la experiencia comparada de los procesos de paz en el mundo, de modo que la no implementación efectiva de medidas como la amnistía se podrá presentar un bloqueo en la materialización de lo acordado por la vía del diálogo.

Esto último, porque la justicia transicional es el equilibro entre la paz y la restauración a través de la reconciliación, que permite tomar medidas adecuadas en beneficio de las víctimas y las próximas generaciones, incluso es el resultado de una negociación política con obligaciones claras y específicas, interpretadas a través del mecanismo de la amnistía

${ }^{40}$ SiKkink, Kathryn (2013), op. cit., nota 29, pp. 273-278. 
como medida excepcional de indulto, la cual no se otorgaba hace veintiséis años en el ordenamiento jurídico colombiano, pero que era necesaria en el tratamiento penal especial para los actores del conflicto armado interno.

Para concluir el presente análisis, verificamos que el acuerdo de paz celebrado entre el gobierno de Colombia y la guerrilla de las FARC (fuerzas armadas revolucionarias de Colombia - ejército del pueblo), da respuesta al cuestionamiento de por qué se quiere acabar con una guerra, más allá de las razones éticas y humanitarias que lo hacen imperativo en estos momentos, Colombia es el país con más experiencia en procesos de paz y post conflicto en el mundo, en virtud de que ha tenido diez procesos de paz en los últimos treinta años, es decir, que al contar con dichos antecedentes, el pueblo puede darse una idea de cómo terminar un conflicto armado y construir paz, mirando su propia experiencia y de esta manera lograr hacer más manejable las diferencias en las relaciones humanas.

\section{Fuentes}

Acuerdo General Para la Terminación Del Conflicto Y la Construcción De Una Paz Estable Y Duradera. [en línea] disponible en: http://www.altocomisionadoparalapaz.gov.co/procesos-y-conversaciones/Documentos\%20compartidos/24-11-2016NuevoAcuerdoFinal.pdf.

Agudelo GiRaldo, Oscar Alexis et al. (2017), La justicia transicional y el rol de la Corte Interamericana de Derechos Humanos. Fundamentación y aplicabilidad de la justicia transicional en Colombia, Bogotá, Universidad Católica de Colombia, Colecciones JUS Público.

Agudelo Mejía, Dimaro et al. (2017), Justicia transicional, Medellín: Universidad de Medellín; Sello editorial Universidad de Medellín.

Beristárn, Antonio (2017) "Hoy y mañana de la justicia y la sociedad en México (los derechos humanos y el combate a la delicuencia)", en La justicia mexicana hacia el siglo XXI, México, UNAM, Instituto de Investigaciones Jurídicas/Senado de la República/LVI Legislatura.

Bernal Cú́llar, Jaime et al. (2016), Reflexiones jurídicas sobre el proceso de paz. Bogotá, Universidad Externado de Colombia, Instituto Colombiano De Derecho Procesal.

Centro Nacional De Memoria Histórica (2013), Informe general ¡Basta ya! Colombia: Memorias de guerra y dignidad, Bogota. [en línea] disponible en: http://www.centrodememoriahistorica.gov.co/descargas/informes2013/bastaYa/basta-ya-colombia-memorias-de-guerra-y-dignidad-2016.pdf

LóPEZ, Claudia (2017), La visión de una generación para transformar a Colombia, TEDxUExternado. [en línea] disponible en: https://www.ted.com/

Congreso De La República De Colombia. Acto Legislativo 01 del 31 de Julio de 2012. [en línea] disponible en: http://www.secretariasenado.gov.co/senado/basedoc/acto_ legislativo_01_2012.html

Corte Constitucional De Colombia. Sentencia C - 579 DE 2013. Magistrado Ponente: Jorge Ignacio Pretelt Chaljub, [en línea] disponible en: http://www.corteconstitucional.gov.co/relatoria/2013/C-579-13.htm 
De La O Soto, José Guadalupe (2016), "El Derecho Internacional de los Derechos Humanos a la luz del caso Radilla Pacheco vs. México", Revista Contribuciones a las Ciencias Sociales, [en línea] disponible en: http:www.eumed.net/rev/cccss/2016/04/ radilla.html

Departamento De Operaciones De Mantenimiento De La Paz, Carta de las Naciones Unidas. Capítulo VI: Arreglo pacífico de controversias. [en línea] disponible en: http:// nacionesunidas.org.co/diapersonaldepaz/departamento-de-operaciones-de-mantenimiento-de-la-paz/

Dirección Para la Acción Integral Contra Minas Antipersonal. [en línea] disponible en: http://www.accioncontraminas.gov.co/Paginas/AICMA.aspx.

Escola De Cultura De Pau (2015), Anuario de Procesos de Paz, [en línea] disponible en: http://escolapau.uab.es/img/programas/procesos/15anuarie.pdf

Ferrajoli, Luigi (2016), "La justicia penal transicional en la Colombia del postconflicto y las garantias para la paz interna", Revista Crítica Penal y Poder, Observatorio del sistema penal y los derechos humanos. Universidad de Barcelona, núm. 10, marzo.

Galtung, Johan (2004), Trascender y transformar: una introducciòn al trabajo de los conflictos, traducción de Montiel y Soriano Editores S.A. de C.V., México.

Gobierno De Colombia, Unidad de Víctimas. [en línea] disponible en: https://www. unidadvictimas.gov.co/

Hueso García, Vicente (2000), "Johan Galtung: la transformación de los conflictos por medios pacíficos", Ideas sobre la prevención de conflictos, núm. 11, Madrid, Instituto Español de Estudios Estratégicos, III series. [en línea] disponible en: http:// www.ieee.es/publicaciones-new/cuadernos-de estrategia/2000/Cuaderno_111.html

Martínez SÁnchez, Mauricio (2016), Reconciliación y castigo en la justicia transicional. Comparación de los modelos Alemán y Colombiano, Bogotá, Grupo editorial Ibáñez, Universidad Nacional de Colombia.

Ley De Víctimas 1448 de 2011. Diario Oficial de la República de Colombia, Bogota D.C., 48096 de junio 10 de 2011. [en línea] disponible en: http://www.alcaldiabogota.gov. co/sisjur/normas/Norma1.jsp?i=43043

Naciones Unidas, Departamento de Operaciones de Mantenimiento de la paz. [en línea] disponible en: http://nacionesunidas.org.co/diapersonaldepaz/departamento-de-operaciones-de-mantenimiento-de-la-paz/

, Apoyo de la consolidación de la paz. La consolidación de la Paz y las Naciones Unidas. [en línea] disponible en: http://www.un.org/es/peacebuilding/pbso/pbun. shtml

Protocolo II adicional a los convenios de Ginebra de 1949 relativo a la protección de las víctimas de los conflictos armados sin carácter internacional, 1977. [en línea] disponible en: https://www.icrc.org/spa/resources/documents/misc/protocolo-ii.htm

SikKInK, Kathryn (2013), La cascada de la justicia. Cómo los juicios de lesa humanidad están cambiando el mundo de la política Traduccion: PRUNES, María Natalia, Buenos Aires, Argentina, Gedisa, S.A. 
Soriano Flores, José Jesús (2018) “Elementos históricos y jurídicos para la conceptualización contemporánea de los Derechos Humanos", Revista Anuario de Derechos Humanos del Instituto de la Judicatura Federal, 1-2017, Suprema Corte de Justicia de la Nación, México, pp. 374-375, [en línea] disponible en: https://www.ijf.cjf.gob. $\mathrm{mx} / /$ Sitio2016/include/sections/Anuario/Capitulos\%20Anuario\%202017/14-Elementos $\% 20$ hist $\%$ C3\%B3ricos\%20y.pdf

URIBE, Diana, Casa de la historia Diana Uribe, [en línea] disponible en: http://www.lacasadelahistoria.com/ 